\title{
Transdermal skin patch based on reduced graphene oxide: A new approach for photothermal triggered permeation of ondansetron across porcine skin
}

Authors: Florina Teodorescu ${ }^{\mathrm{a}}$, Gurvan Quéniat ${ }^{\mathrm{ab}}$, Catherine Foulon ${ }^{\mathrm{c}}$, Marie Lecoeur ${ }^{\mathrm{c}}$, Alexandre Barras ${ }^{\mathrm{a}}$, Samia Boulahneche ${ }^{\mathrm{ad}}$, Mohmaed Salah Medjram ${ }^{\mathrm{d}}$, Thomas Hubert ${ }^{\mathrm{e}}$, Amar Abderrahmani $^{\mathrm{b}}$, Rabah Boukherroub ${ }^{\mathrm{a}}$, SabineSzunerits ${ }^{\mathrm{a}}$

a Univ. Lille, CNRS, Centrale Lille, ISEN, Univ. Valenciennes, UMR 8520 - IEMN, F-59000 Lille, France

b University Lille, CNRS, CHU Lille, Institut Pasteur de Lille, European Genomic Institute of Diabetes (EGID) FR 3508, UMR 8199, Génomique Intégrative et Modélisation des Maladies Métaboliques, F-59000 Lille, France

c Univ. Lille, EA 7365 - GRITA-Groupe de Recherche sur les formes Injectables et les Technologies Associées, F-59000 Lille, France

d Laboratoire de Génie Chimique et Environnement de Skikda (LGCES), Université 20 Août 1955-Skikda, Algeria

e University Lille 2, CHU Lille, INSERM, European Genomic Institute of Diabetes (EGID), INSERM, UMR 1190, F-59000 Lille, France

First published: 30/11/2016

DOI: $\underline{10.1016 / j . j \text { conrel.2016.11.029 }}$

\begin{abstract}
.
The development of a skin-mounted patch capable of controlled transcutaneous delivery of therapeutics through thermal activation provides a unique solution for the controlled release of active principles over long-term periods. Here, we report on a flexible transdermal patch for photothermal triggered release of ondansetron (ODS), a commonly used drug for the treatment of chemotherapy-induced nausea and vomiting and used as model compound here. To achieve this, a dispersion of ODS-loaded reduced graphene oxide (rGO-ODS) nanosheets were deposited onto Kapton to produce a flexible polyimide-based patch. It is demonstrated that ODS loaded Kapton/rGO patches have a high drug delivery performance upon irradiation with a continuous laser beam at $980 \mathrm{~nm}$ for $10 \mathrm{~min}$ due to an induced photothermal heating effect. The ability of ODS impregnated Kapton/rGO patches as transdermal delivery scaffolds for ODS across the skin is in addition investigated using porcine ear skin as a model. We show that the cumulative quantity and flux of ODS passing the skin are highly depending on the laser power density used. At $5 \mathrm{~W} \mathrm{~cm}^{-2}$ irradiation, the ODS flux across pig skin was determined to be $1.6 \mu \mathrm{g} \mathrm{cm}^{-2} \mathrm{~h}^{-1}$ comparable to other approaches. The use of tween 20 as skin enhancer could significantly increase the ODS flux to $13.2 \mu \mathrm{g} \mathrm{cm}^{-2} \mathrm{~h}^{-1}$. While the skin penetration enhancement is comparable to that obtained using other well-known permeation enhancers, the actual superiority and interest of the proposed approach is that the Kapton/rGO photoactivatable skin patch can be loaded with any drugs and therapeutics of interest, making the approach extremely versatile. The on demand delivery of drugs upon local laser irradiation and the
\end{abstract}

DOI: https://doi.org/10.1016/j.jconrel.2016.11.029 - Journal: Journal of Controlled Release - Postprint 
possibility to reload the interface with the drug makes this new drug administration route very appealing.

\section{Graphical abstract}

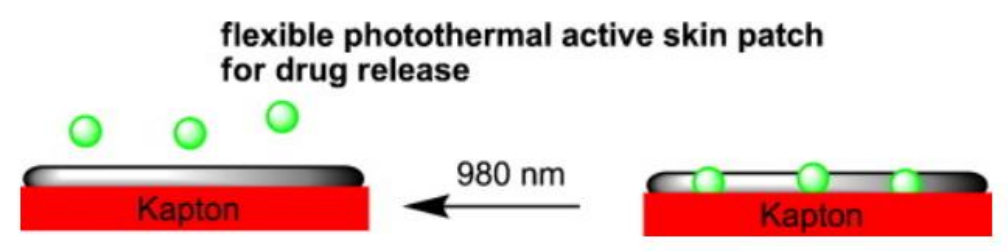

\section{Introduction}

Recent achievements in materials science and nanotechnology have led to the development of various suited materials as carriers of drugs and therapeutics [1-9]. Particularly, graphenebased materials have gained a great deal of interest in this domain due to their high loading capacity [3,10-16]. For example, the loading ratio (weight ratio of loaded drug to carrier) of graphene oxide (GO) towards doxorubicin hydrochloride, an anticancer drug, could reach up to $200 \%$, much higher than that of other nanocarriers such as nanoparticles with a loading ratio lower than $100 \%$ [13].

Various external stimuli have been employed to initiate drug release from graphene-based matrices, including pH [13,14,17], electrical [18], electrochemical [10,11,19] and light [15,20]. For on-demand release of drugs with high spatial and temporal resolution, light stimulation has shown to be an effective approach. Such photo-controlled drug delivery systems are often based on light induced photoreactions, which trigger drug release from the nanocarriers [6,21,22]. In the case of graphene-based drug-loaded scaffolds, near-infrared (NIR) light triggered photothermal effects are above all used to drive the release of therapeutics $[15,20,23]$. The effectiveness of graphene as NIR-absorbing photothermal agent compared to other carbon allotropes is enhanced by the rapid light-to-heat conversion of reduced graphene oxide (rGO) under low-power NIR irradiation [24]. The readily manufacturing of NIR laser pointer devices and the transparency of tissue in the NIR region make such delivery approaches amendable to clinical settings [25]. Besides a recent report by Matteini et al., where photothermal films composed of dispersion of rGO nanosheets loaded with doxorubicin in chitosan scaffolds have been proposed as delivery systems [20], photoablation of tumors by cellular uptake of graphenebased nanomatrices is most widely investigated [16,26]. However, photothermal active patches mounted on the skin, capable of controlled transcutaneous delivery of therapeutics through thermal activation, might provide a unique solution for the controlled release of active principles over long-term periods. It could thus represent a promising biomedical technology for the treatment of certain types of diseases such as cancer, diabetes and chronic pain.

In this work, the development of a drug loaded transdermal skin patch, where the embedded therapeutics can be released at demand using a photothermal trigger is presented (Fig. 1).

DOI: https://doi.org/10.1016/j.jconrel.2016.11.029 - Journal: Journal of Controlled Release - Postprint 
Transdermal therapeutic systems, mostly known under the name of transdermal patches, are systems that deliver effective amount of drugs to the systemic circulation via the skin [27-30]. Compared to oral systems, they have the advantage of overcoming first-pass metabolism of drugs in the gut and liver, improved patient compliance and reduced side effects, and have proven to be of great therapeutic utility. However, there are several factors which make the transdermal delivery of various drugs a challenging issue. The unique structural features of the stratum corneum, the outermost layer of the skin, only permits lipophilic drugs with small molecular weight $(<500 \mathrm{Da})$ to penetrate via passive diffusion [31]. A variety of methods have been tested to enhance the permeability of the stratum corneum. The design of chemical formulations, with chemical skin enhancers such as solvents and surfactants, as well as the synthesis of co-drug modified therapeutics to disrupt the structure of the stratum corneum, have been proposed [32-34]. On the other hand, physical techniques including mechanical and thermal approaches have been investigated to generate micrometer disruptions in the stratum corneum structure. The use of microneedles filled with drugs is one of the painless strategies to pierce the stratum corneum and to enhance drug permeation [10,29,35]. Laser ablationenhanced transdermal drug delivery using wavelengths of $\mathrm{CO}_{2}$ and Er:YAG lasers at 10,600 nm and $2940 \mathrm{~nm}$ have been investigated to heat the skin to hundreds of degrees for a very short period of time in order to disrupt the stratum corneum structure [36,37]. Other studies have shown that heat can be used as an external trigger to increase skin permeability and is expected to enhance in addition blood vessel permeability, thus facilitating transdermal drug delivery [38,39]. Temperature dependent drug release through a hyperthermia effect is also one of the approaches used to trigger efficient drug release from graphene nanomatrices $[15,20,23]$.

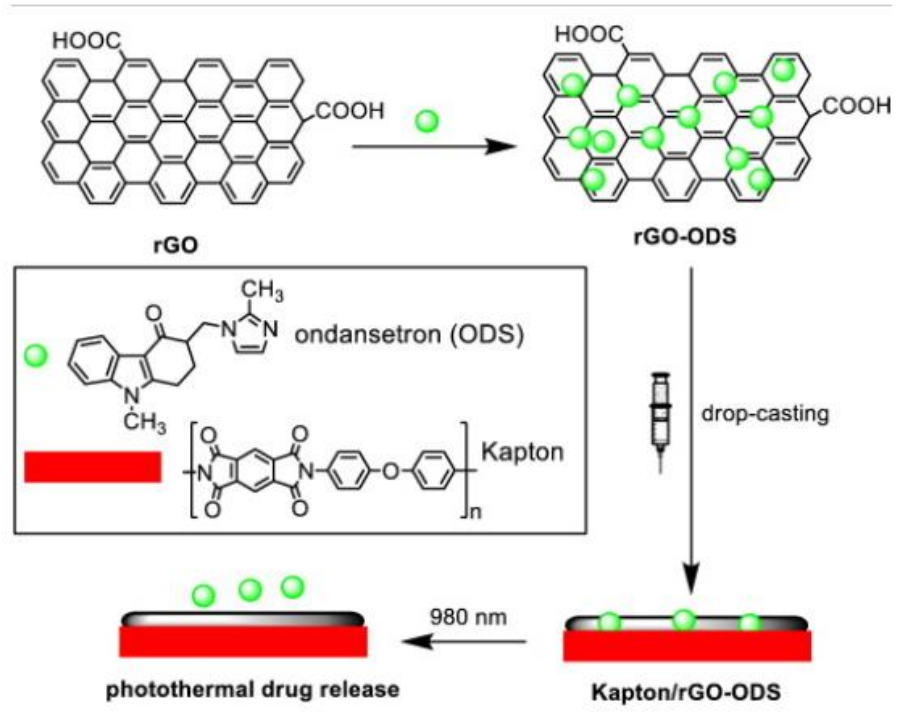

Figure 1.

Schematic illustration of the fabrication of a flexible photoactive skin-patch based on ODS-loaded rGO deposited onto Kapton.

We investigate, here, if a transdermal skin patch obtained by impregnation of rGO nanosheets with ondansetron (ODS) as a model drug and deposited onto a flexible polyimide-based interface, Kapton, can deliver therapeutics across the skin at demand using NIR photothermal triggering to initiate drug release from the patch (Fig. 1). NIR light causes little tissue absorption and minimal thermal effect, but can penetrate up to $10 \mathrm{~cm}$ into soft tissues [40]. ODS, a selective 3

DOI: https://doi.org/10.1016/j.jconrel.2016.11.029 - Journal: Journal of Controlled Release - Postprint 
5-HT3 receptor antagonist used in the treatment of nausea and vomiting related to cancer chemotherapy [41] was chosen as model drug. ODS appears to be a well suited transdermal agent as it has a molecular weight of $293 \mathrm{Da}$, a $\log \mathrm{P}$ value of 2.07 , and a $\mathrm{pK}_{\mathrm{A}}$ of about 7.4 $[28,42]$. As passive transdermal delivery of ODS is very low, skin enhancers are normally added to pharmaceutical ODS formulations to enable in vitro skin permeation [43-45]. The interest in ODS motivated us to use this drug for the loading of the developed transdermal skin patch and to investigate the efficacy for ODS delivery through the skin upon NIR irradiation of the patch. With a $\mathrm{pKa}$ of 7.6, thus being positively charged at stratum corneum $\mathrm{pH}$ (between 4.5 and 6.8), it is hoped furthermore that the interaction with negatively charged cell junctions in the stratum corneum will result in enhanced percutaneous penetration activity.

\section{Experimental section}

\subsection{Materials}

Hydrogen peroxide $\left(\mathrm{H}_{2} \mathrm{O}_{2}\right)$, sulfuric acid $\left(\mathrm{H}_{2} \mathrm{SO}_{4}\right)$, sodium hydroxide $(\mathrm{NaOH})$, dimethylsulfoxide (DMSO), hydrazine hydrate, acetonitrile $\left(\mathrm{CH}_{3} \mathrm{CN}\right)$ and Tween 20 were purchased from Sigma-Aldrich (Darmstadt, Germany) and used as received. Ondansetron (ODS) and graphene oxide (GO) were purchased from Biotrend (Zurich, Switzerland) and Graphenea (Spain), respectively. Kapton ${ }^{\circledR}$ HN Polyimide foils with a thickness of $125 \mu \mathrm{m}$ were obtained from DuPont (Circleville, OH, USA).

\subsection{Synthesis of reduced graphene oxide (rGO)}

Graphene oxide (GO) was synthesized from graphite powder by a modified Hummers' method [46]. $5 \mathrm{mg}$ of the synthesized GO were dispersed in $1 \mathrm{~mL}$ of water and exfoliated through ultrasonication for $3 \mathrm{~h}$. This aqueous suspension of GO was used as a stock suspension in subsequent experiments. The reduction of $\mathrm{GO}$ to reduced graphene oxide (rGO) was performed by adding hydrazine hydrate $(0.50 \mathrm{~mL}, 32.1 \mathrm{mM})$ to $5 \mathrm{~mL}$ GO aqueous suspension $\left(0.5 \mathrm{mg} \mathrm{mL}^{-1}\right)$ in a round bottom flask and heated in an oil bath at $100{ }^{\circ} \mathrm{C}$ for $24 \mathrm{~h}$. During this time, the reduced GO gradually precipitates out of the solution. The product was isolated by filtration over a polyvinylidene difluoride (PVDF) membrane with a $0.45 \mu \mathrm{m}$ pore size, washed copiously with water $(5 \times 20 \mathrm{~mL})$ and methanol $(5 \times 20 \mathrm{~mL})$, and dried in an oven at $60{ }^{\circ} \mathrm{C}$ for $6 \mathrm{~h}[47]$.

\subsection{Loading of rGO with ondansetron (ODS)}

rGO (1-5 mg mL $\left.{ }^{-1}\right)$ was sonicated with ondansetron $\left(500 \mu \mathrm{g} \mathrm{mL}^{-1}\right)$ for $2 \mathrm{~h}$ under stirring. All samples were centrifugated at 13,500 $\mathrm{rpm}$ for $30 \mathrm{~min}$. The concentration of ODS loaded onto the rGO matrix was determined using UV/Vis spectrometry (see Fig. 3A). A calibration curve (inset Fig. 3A) was established at $310 \mathrm{~nm}$ using a series of ODS solutions of different concentrations. The concentration of ODS remaining in the supernatant solution used for loading of rGO was first determined using the calibration curve. The ODS concentration in the patch was calculated according to equation

$$
[O D S]_{r G O}=[O D S]_{\text {initial }}-[O D S]_{\text {supernatent }}
$$

4

DOI: https://doi.org/10.1016/j.jconrel.2016.11.029 - Journal: Journal of Controlled Release - Postprint 
with $[O D S]_{\mathrm{rGO}}=$ concentration of ODS on the $\mathrm{rGO}$ matrix $\left(\mu \mathrm{g} \mathrm{mL} \mathrm{L}^{-1}\right)$

with $[O D S]_{\text {initial }}=$ initial concentration of ODS in solution $\left(500 \mu \mathrm{g} \mathrm{mL}^{-1}\right)$

with $[O D S]_{\text {supernatent }}=$ concentration of ODS in supernatant $\left(\mu \mathrm{g} \mathrm{mL}^{-1}\right)$

\subsection{Preparation of Kapton/rGO-ODS flexible skin patch}

Kapton foils $\left(10 \times 10 \mathrm{~mm}^{2}\right)$ were cleaned with acetone in an ultrasonic water bath for $30 \mathrm{~min}$, followed with isopropanol for $10 \mathrm{~min}$ and then dried under a nitrogen flow. The cleaned Kapton foils were modified with rGO-ODS by drop-casting $(100 \mu \mathrm{L})$ three times, followed by drying at room temperature for several hours.

\subsection{Characterization of the ondansetron loaded Kapton/rGO}

\subsubsection{Scanning electron microscopy (SEM)}

SEM images were obtained using an electron microscope ULTRA 55 (Zeiss, France) equipped with a thermal field emission emitter and three different detectors (EsB detector with filter grid, high efficiency In-lens SE detector and Everhart-Thornley Secondary Electron Detector).

\subsubsection{UV/Vis measurements}

Absorption spectra were recorded using a Perkin Elmer Lambda UV/Vis 950 spectrophotometer in a $1-\mathrm{cm}$ quartz cuvette. The wavelength range was $200-1100 \mathrm{~nm}$.

\subsubsection{Zeta potential measurements}

The zeta potential was determined using dynamic light scattering principle (Malvern Zetasizer, NanoZS). The values of zeta potential of $\mathrm{rGO}\left(50 \mu \mathrm{g} \mathrm{mL}^{-1}\right)$ and their mixtures with ODS in water at various $\mathrm{pH}(4,6,7$ and 9$)$ were recorded.

\subsubsection{Contact angle measurements}

Water contact angles were measured using $2 \mu \mathrm{L}$ of deionized water. A remote-computer controlled goniometer system (DIGIDROP by GBX, France) was used for measuring the contact angles. The accuracy is $\pm 1^{\circ}$. All measurements were performed in ambient atmosphere at room temperature.

\subsection{HPLC/UV method for quantification of ondansetron permeation through skin}

Chromatographic analyses were performed using a Waters system (Milfors, MA, USA) equipped with a gradient quaternary $600 \mathrm{E}$ metering pump, an online degasser apparatus, a 717 plus autosampler and a 996 photodiode array detector. Data were collected and processed on a computer running with Empower solftware (version 2) from Waters. Separations were carried out on a reversed-phase Kinetex C18 $(100 \times 4.60 \mathrm{~mm}$ i.d., $2.6 \mu \mathrm{m})$ column (Phenomenex, Le Pecq, France) preceded by a guard C18 column $(1 \times 4.60 \mathrm{~mm})$. Isocratic elution was performed

DOI: https://doi.org/10.1016/j.jconrel.2016.11.029 - Journal: Journal of Controlled Release - Postprint 
at $1 \mathrm{~mL} \mathrm{m^{-1 }}$ with a mobile phase consisting of $\mathrm{H}_{2} \mathrm{O} /$ acetonitrile $(80 / 20-\mathrm{v} / \mathrm{v})$ mixture, containing $0.1 \%$ formic acid. The column was thermostated at $25^{\circ} \mathrm{C}$. Samples were filtered through a $0.45 \mu \mathrm{m}$ regenerated cellulose membrane prior to loading the column (injection volume: $20 \mu \mathrm{L}$ ). Detection was performed at $310 \mathrm{~nm}$. This method permits the analysis of ODS in $<6$ min with a linear range between 0.1 and $100 \mu \mathrm{g} \mathrm{L}^{-1}$, according to a linear regression $\left(\mathrm{R}^{2}>0.999\right)$.

\subsection{Photothermal release of ODS into solution}

Release experiments were performed into $1 \mathrm{~mL}$ deionized water. The skin patch was irradiated with a continuous mode laser (Gbox model, Fournier Medical Solution) with an output light at $980 \mathrm{~nm}$ at various power densities $\left(1-10 \mathrm{~W} \mathrm{~cm}^{-2}\right)$ for various time intervals (1-60 min). Thermal images were captured by an Infrared Camera (Thermovision A40) and treated using ThermaCam Researcher Pro 2.9 software. The quantity of drug released was determined by assessment of ondansetron concentration in the supernatant after irradiation, by UV spectrometry method, at $310 \mathrm{~nm}$, using a calibration curve with ODS concentration ranging from 1 to $100 \mu \mathrm{g} \mathrm{mL}{ }^{-1}$.

\subsection{Skin permeation experiments}

Skin permeation studies were performed using fresh porcine ear skin purchased in a local slaughterhouse. After thorough rinsing the pig ear with distilled water, the cartilage and the adipose tissue layer were removed with the aid of a surgical scalpel. The skin was gently shaved and cut into $1.8 \mathrm{~cm}^{2}$ circular pieces. After measurement of its thickness using a digimatic micrometer (Mitutoyo, France), the skin was used immediately thereafter for diffusion experiments.

ODS skin diffusion experiments were carried out using static Franz diffusion cells (SES GmbH, Analyse System, Bechenheim, Germany) exhibiting an effective area of $0.64 \mathrm{~cm}^{2}$. After filling the receptor compartment with degassed PBS $(1 \times, \mathrm{pH} 7.4)$, the solution was maintained at $32{ }^{\circ} \mathrm{C}$ and stirred with a magnetic stirring bar at around $500 \mathrm{rpm}$. The porcine skin was carefully clamped between the donor and the receptor compartment $(3.1 \mathrm{~mL})$. Pre-incubation in the receptor compartment medium for $1 \mathrm{~h}$ was performed before the ODS modified skin patch was applied to the skin previously wetted with $100 \mu \mathrm{L}$ of water to insure contact between the patch and the skin. The diffusion experiment was started and followed for $6 \mathrm{~h}$. The ODS modified skin patch was irradiated with a continuous wave laser at $980 \mathrm{~nm}$ for $10 \mathrm{~min}$ using different power densities $\left(0-10 \mathrm{~W} \mathrm{~cm}^{-2}\right)$, just after the patch application. At determined time intervals $(1 \mathrm{~h}), 250 \mu \mathrm{L}$ aliquots of diffused solution were removed from the receptor compartment and analysed by HPLC. After each sampling, an equal volume of fresh diffusion medium was added to the receptor compartment to maintain a constant volume. All experiments were performed in triplicates.

The release and permeation profiles were determined by plotting the cumulative amount of ODS in the receptor compartment ( $\left.\mathrm{Q}_{\exp }\right)($ Eq. (2)) against time.

$$
Q_{\text {exp }}=c_{n} \times V+\sum_{i=1}^{n-1} V_{s} \times c_{i}
$$

DOI: https://doi.org/10.1016/j.jconrel.2016.11.029 - Journal: Journal of Controlled Release - Postprint 
with $Q_{\exp }=$ cumulative amount of ODS diffused through the skin $(\mu \mathrm{g})$

$c_{n}=$ concentration of ODS $\left(\mu \mathrm{g} \mathrm{mL}^{-1}\right)$ determined at the $\mathrm{n}^{\text {th }}$ sampling interval

$\mathrm{V}=$ volume of the acceptor phase (receptor compartment) $(\mathrm{mL})$

The ODS flux $(J)$ was determined according to Eq. (3):

$$
J=A / S
$$

with $J=$ flux of ODS through the skin $\left(\mu \mathrm{g} \mathrm{cm}^{-2} \mathrm{~h}^{-1}\right)$

A = linear slope of the cumulative amount versus time curves in equilibrium conditions $\left(\mu \mathrm{g} \mathrm{h}^{-1}\right)$

$\mathrm{S}=$ surface of the membrane of the Franz cell $\left(0.64 \mathrm{~cm}^{2}\right)$

\subsection{Effect of surfactant Tween 20 on skin permeation of ODS}

The effect of Tween 20 on the permeation efficiency of ODS through pig skin was evaluated in two ways. In the first approach, Tween 20 was integrated into the rGO/ODS mixture by sonicating rGO $\left(1 \mathrm{mg} \mathrm{mL}^{-1}\right)$ with ondansetron $\left(500 \mu \mathrm{g} \mathrm{mL}^{-1}\right)$ and Tween $20\left(500 \mu \mathrm{g} \mathrm{mL}^{-1}\right)$ for $2 \mathrm{~h}$ under stirring. The samples were centrifugated at $13.500 \mathrm{rpm}$ for $30 \mathrm{~min}$, washed with water and drop casted (100 $\mu \mathrm{L}$, three times) onto cleaned Kapton foils, followed by drying at room temperature for several hours.

The other experimental set up consisted in applying the ODS modified skin patch to the skin previously wetted with $200 \mu \mathrm{L}$ of a mixture of water/tween $20(85 / 15 \mathrm{w}: \mathrm{w} \%)$. The diffusion experiments were performed as explained in 2.8 .

\subsection{Evaluation of ODS trapped in the skin}

To estimate the amount of ODS trapped in the skin, the skin was added into water/ice mixture for $10 \mathrm{~min}$ and sonicated in the presence of $\mathrm{ZnO}_{2}$ beads ( $4 \mathrm{~mm}$ in diameter), before being centrifuged for $30 \mathrm{~min}$ at $13500 \mathrm{rpm}$ using an ultracentrifuge (Mini Scan Fuge ORIGIO). The liquid phase was collected and filtrated through a $0.1 \mu \mathrm{m}$ Nylon filter (Whatman Puradisc $13 \mathrm{~mm}$ ) and the amount of ODS determined by HPLC/UV.

\subsection{Skin staining and histology}

Immediately after the laser release studies, the porcine skin was cleaned in water, dissected and placed in paraformaldehyde $(4 \% \mathrm{v} / \mathrm{v})$ for $24 \mathrm{~h}$ in order to fix the tissue. The samples were paraffined, sectioned and stained with the Masson's trichrome dye.

DOI: https://doi.org/10.1016/j.jconrel.2016.11.029 - Journal: Journal of Controlled Release - Postprint 


\section{Results and discussion}

\subsection{Design and characteristics of rGO/Kapton flexible photoactive skin patches}

The fabrication of a flexible photoactive skin patch is based on drop-casting a suspension of drug-loaded rGO onto $1 \mathrm{~cm} 2$ large films of poly (4,4'-oxydiphenylene-pyromellitimide), registered under the name Kapton (Fig. 1).

The choice of Kapton as a patch material is based on some of its interesting physico-chemical properties. Highly aromatic polyimide resins such as Kapton have high thermal stability $\left(>300{ }^{\circ} \mathrm{C}\right)$, a high glass transition temperature $\left(\mathrm{T}_{\mathrm{g}}>20{ }^{\circ} \mathrm{C}\right)$, proven chemical resistance as well as excellent flexibility and adhesive properties [48-50]. The optical absorption of GO, rGO, rGO/Kapton is depicted in Fig. 2A. The absorbance intensity at $980 \mathrm{~nm}$ was found to be boosted in the Kapton film. The SEM image of a rGO/Kapton matrix (Fig. 2B) shows that the entire interface is coated with a thin film of wrinkling paper-like structures as expected for rGO. The rGO/Kapton patches are stable in air for several months.

(A)

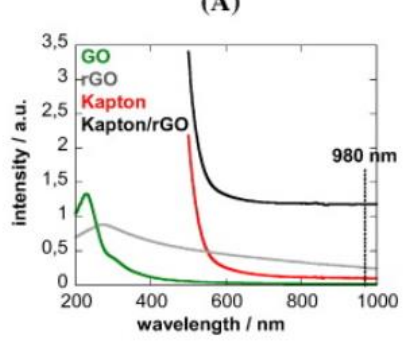

(C)

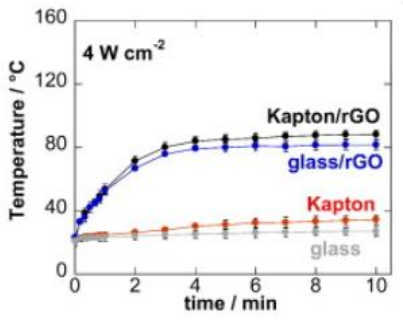

(B)
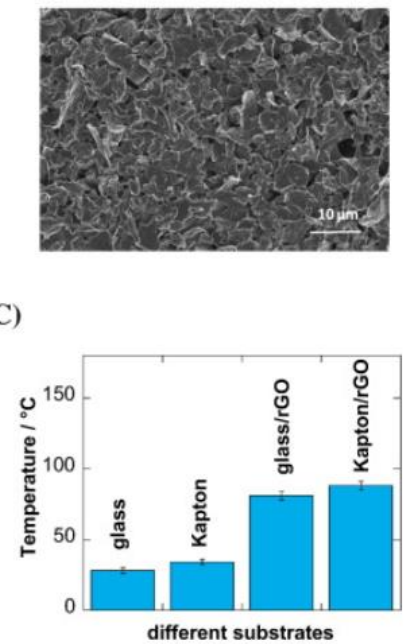

Figure 2.

(A) UV/Vis absorption spectra of an aqueous solution of GO (2 mg mL-1, green), quartz interfaces coated with rGO thin films by drop-casting ( 2 $\mathrm{mg} \mathrm{mL}-1$, three times, grey), Kapton film (red) and Kapton coated by drop casting with $\mathrm{rGO}(2 \mathrm{mg} \mathrm{mL}-1$, three times black) $(2 \mathrm{mg} \mathrm{mL}-1)$;

(B) SEM image of rGO loaded Kapton patch; (C) Comparison of photothermal heating capacity of glass (grey), Kapton (red), glass/rGO (blue) and Kapton/rGO (black) of water under NIR illumination $(980 \mathrm{~nm}$ ) for $10 \mathrm{~min}$ at $4 \mathrm{~W} \mathrm{~cm}-2$ together with final temperature in form of a bar diagram.

DOI: https://doi.org/10.1016/j.jconrel.2016.11.029 - Journal: Journal of Controlled Release - Postprint 


\subsection{Photothermal properties of the skin patch}

As the aim of the work is the development of a skin patch that can be activated by a continuouswave NIR to provide on-demand drug delivery over an extended period of time due to an induced temperature change, the photothermal heating ability of the patch was determined. The use of NIR light in the range of 700-1100 nm is necessary, as the absorption of NIR photons of the skin is minimal in this spectral region. The wavelength of $980 \mathrm{~nm}$ is widely used in the construction of biomedical lasers and thus was used throughout the work. While this wavelength falls within the vibration onset of water molecules with consequently higher absorption cross section, absorption by water molecules at $980 \mathrm{~nm}$ is not causing problems in most cases [51,52], and might be beneficial for the photothermal delivery across the skin. One of the main advantages using $980 \mathrm{~nm}$ excitation rather than $810 \mathrm{~nm}$ is associated with deeper tissue penetration and a low level degradation of biomolecules and cellular photo-damage. The photothermal heating ability of Kapton, and rGO/Kapton was determined under NIR irradiation (Fig. 2C). Even though Kapton has a strong absorption at $980 \mathrm{~nm}$, it shows no photothermal heating ability even under high laser power irradiation of $4 \mathrm{~W} \mathrm{~cm}^{-2}$. Upon coating with $\mathrm{rGO}$, temperatures up to $88{ }^{\circ} \mathrm{C}$ are reached within $10 \mathrm{~min}$. To evaluate if Kapton has any synergistic effect on the final temperature, the photothermal heating curves of glass and glass modified by drop casting with rGO are recorded (Fig. 2C). Glass alone does not heat as expected. The glass/rGO interface exhibits a somewhat smaller final solution temperature of $81{ }^{\circ} \mathrm{C}$ compared to the $88^{\circ} \mathrm{C}$ achieved using $\mathrm{rGO} /$ Kapton, indicating a rather small impact of Kapton on the photothermal properties of the patch.

\subsection{Loading of skin patch with ondansetron (ODS)}

ODS was integrated into rGO by sonicating a suspension of rGO $\left(1-5 \mathrm{mg} \mathrm{mL}^{-1}\right)$ in water (pH 7) with $500 \mu \mathrm{g} \mathrm{mL}^{-1}$ of ODS for $4 \mathrm{~h}$. The loading mechanism is believed to occur through $\pi-\pi$ stacking and/or charge interactions between $\mathrm{rGO}$ and the positively charged pyridine network of ODS, although other contributions such hydrogen bonding and/or van der Waals interactions cannot be excluded. The loading capacity of rGO for ODS was evaluated by measuring the concentration of ODS in solution before and after loading using UV/Vis spectrometric measurements at $310 \mathrm{~nm}$. At this wavelength, ODS displays a well-defined absorption band which scales linearly with its concentration in solution (Fig. 3A). As can be seen from Fig. 3B, ODS loading increased upon increasing the ratio of [rGO]/[ODS]. A loading efficiency of $98 \%$ was reached for a rGO/ODS ratio of 4 (Fig. 3C). Further increase of the [rGO]/[ODS] ratio to 6 did not result in any increase of ODS loading at $\mathrm{pH} 7$. The loading capacity of rGO was found to be $\mathrm{pH}$ dependent, with higher ODS loading at $\mathrm{pH} \geq 7$ (Fig. 3D). With a pKa of 7.6, under $\mathrm{pH} 7.6$ ODS is mainly in a cationic form $(99.97 \%, 97.5 \%$ and $80 \%$ at $\mathrm{pH} 4,6$ and 7, respectively) whereas at $\mathrm{pH} 9$ it is mainly neutral (96.2\%). As $\pi-\pi$ stacking interactions are $\mathrm{pH}$ independent, the higher ODS loading under basic conditions might be due to a better solubility of ODS.

DOI: https://doi.org/10.1016/j.jconrel.2016.11.029 - Journal: Journal of Controlled Release - Postprint 
(A)

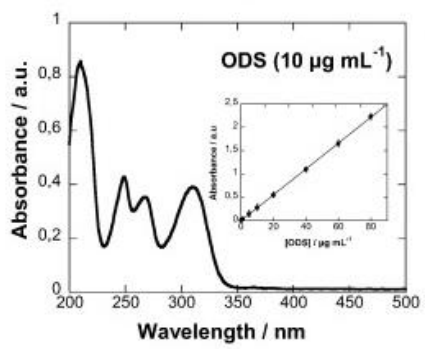

(C)

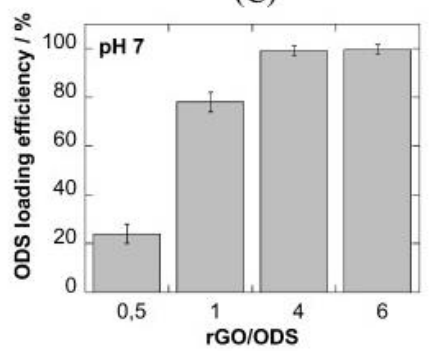

(E)

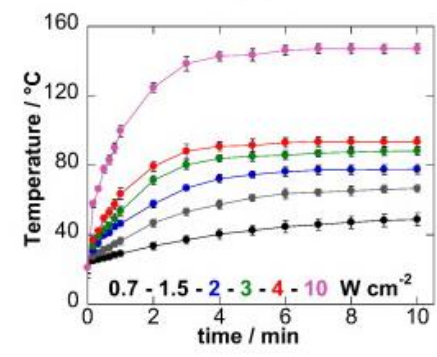

(B)

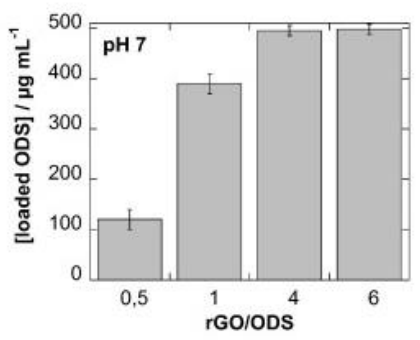

(D)

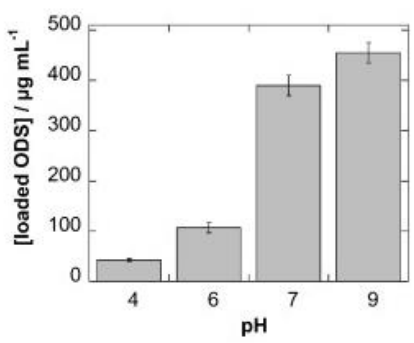

(F)

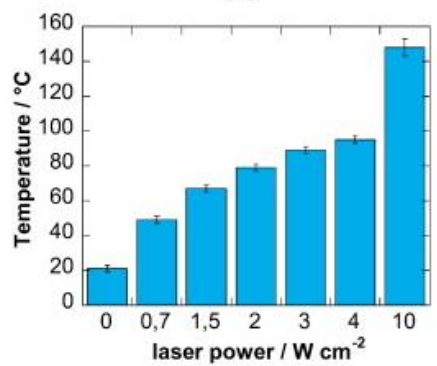

\section{Figure 3}

ODS loading on the skin patch:

(A) UV/Vis spectrum of ODS solution (inset: calibration curve;

(B) ODS (500 $\left.\mu \mathrm{g} \mathrm{mL}^{-1}\right)$ loading capacity of rGO as a function of rGO content at $\mathrm{pH} 7$;

(C) ODS loading efficiency;

(D) Influence of $\mathrm{pH}$ on ODS loading $\left(500 \mu \mathrm{g} \mathrm{mL}^{-1}\right)$ onto $\mathrm{rGO}\left(2 \mathrm{mg} \mathrm{mL}^{-1}\right)$;

(E) Photothermal heating curves of water using a Kapton/rGO patch under NIR illumination $(980 \mathrm{~nm})$ at different laser power densities using a continuous wave laser;

(F) Change in water solution temperature $(1 \mathrm{~mL})$ during illumination of Kapton-rGO patch at $980 \mathrm{~nm}$ for $10 \mathrm{~min}$ as a function of laser power density.

The photothermal heating curves as a function of laser power of a patch formed by drop-casting a rGO-ODS (ratio of 4) onto Kapton are seen in Fig. 3E, F. The presence of ODS does not impact the solution temperature as the same temperatures were reached at $4 \mathrm{~W} \mathrm{~cm}^{-2}$ for Kapton/rGO-ODS (Fig. 3E) and Kapton/rGO (Fig. 2C). Depending on the laser power density used, the solution temperature can be tuned between 20 and $155^{\circ} \mathrm{C}$. This wide temperature range achieved allows investigation of the effect of temperature on skin disruption and on drug delivery. In the case of laser ablation-enhanced transdermal drug delivery, the skin gets heated 10

DOI: https://doi.org/10.1016/j.jconrel.2016.11.029 - Journal: Journal of Controlled Release - Postprint 
to hundreds of degrees for very short time periods ( $\mu \mathrm{s}-\mathrm{ms}$ ), which perforates or removes the stratum corneum (SC): temperatures between 100 and $150{ }^{\circ} \mathrm{C}$ results in disordering of the SC lipid structures; temperatures between 150 and $200^{\circ} \mathrm{C}$ disrupt the SC keratin network structures, while temperatures above $300{ }^{\circ} \mathrm{C}$ result in a decomposition and vaporization of keratin to create micropores in the SC, which leads to increased skin permeability [53]. Pulsed $\mathrm{CO}_{2}$ and Er:YAG lasers are required, because their emitting mid-infrared wavelength matches the absorption wavelength of water molecules, resulting in strong light absorption and skin heating [36,54]. NIR light alone, as used here, is however not sufficient to remove the stratum corneum.

\subsection{Release of ondansetron (ODS) from ODS Kapton/rGO patches}

Before determining the amount of ODS released during photothemal activation, the long term stability of the ODS loaded Kapton/rGO patch was established. Around $5 \pm 2 \%$ of ODS desorbs from the patch after 1 day immersion in a solution of $\mathrm{pH} 7$, indicating a stable interface over time. Fig. 4A displays the amount of photochemically released ODS upon illumination of the patch at $980 \mathrm{~nm}$ for $10 \mathrm{~min}$ with a continuous laser at different laser powers. The proportion of ODS released increases with increasing the laser power density. At $0.7 \mathrm{~W} \mathrm{~cm}^{-1}$, only a small fraction of ODS was released. A temperature of $50^{\circ} \mathrm{C}(\underline{\text { Fig. } 3 \mathrm{~F}})$ seems not sufficient to change the affinity between ODS and rGO. At a laser power of $3 \mathrm{~W} \mathrm{~cm}^{-1}$, corresponding to $89{ }^{\circ} \mathrm{C}$, the ODS proportion released after 10 min reached a maximal value. Despite increasing the laser power density to $10 \mathrm{~W} \mathrm{~cm}^{-1}$ did not increase further ODS release (Fig. 4A). An important feature of the patch is its reusability. Reloading of ODS onto the patch after photothermal release could be performed with the same efficiency for at least 6 cycles (Fig. 4B), making the patch of particular interest for the development of on-demand delivery platforms. The ODS loaded patch also provides sustained drug release upon NIR trigger. Fig. 4C exhibits the total amount of ODS released from the patch over 9 days when activated once a day for 10 min by laser illumination at $980 \mathrm{~nm}\left(3 \mathrm{~W} \mathrm{~cm}^{-2}\right)$. While in the first day $15 \%\left(75 \mu \mathrm{g} \mathrm{mL}^{-1}\right)$, on the second day $14 \%\left(70 \mu \mathrm{g} \mathrm{mL}^{-1}\right)$ and the third day $10 \%\left(50 \mu \mathrm{g} \mathrm{mL}^{-1}\right)$ of ODS were released from the matrix, thereafter the amount is kept constant at $8.8 \%\left(44 \mu \mathrm{g} \mathrm{mL}^{-1}\right)$. This experiment demonstrates that the photoactivated Kapton/rGO interface facilitates the release of multiple drug doses at demand using the same patch, without being recharged. Under the chosen conditions the patch can be indeed used for a least a week safely.

DOI: https://doi.org/10.1016/j.jconrel.2016.11.029 - Journal: Journal of Controlled Release - Postprint 

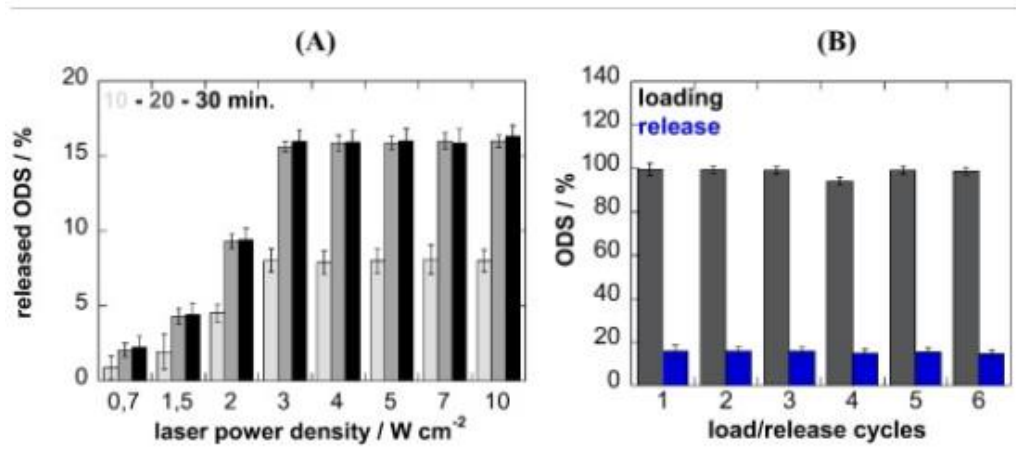

(C)

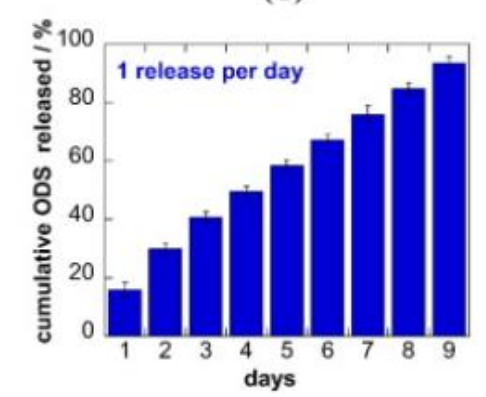

(D)

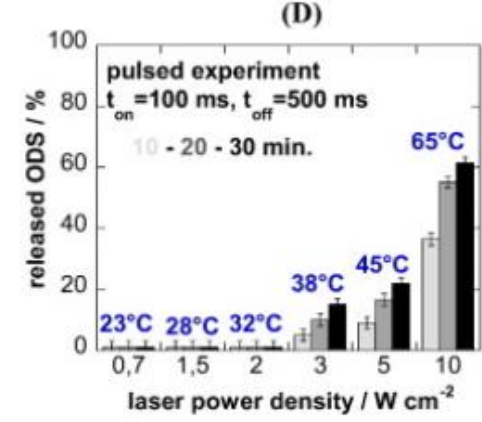

Figure 4.

ODS release:

(A) Concentration of photothermally released ODS into water $(\mathrm{pH} 7)$ from Kapton/rGO patch (formed by mixing $500 \mu \mathrm{g} \mathrm{mL}^{-1}$ ODS with $1 \mathrm{mg} \mathrm{mL}^{-1}$ rGO) using a continous wave laser at $980 \mathrm{~nm}, 0.7-10 \mathrm{~W} \mathrm{~cm}^{-2}$ with illumination time of $10 \mathrm{~min}$;

(B) Reloading (at pH 7 with $500 \mu \mathrm{g} \mathrm{mL}^{-1}$ ) and release of ODS (980 nm, $10 \mathrm{~min}, 3 \mathrm{~W} \mathrm{~cm}^{-2}$ ) from patch for 6 cycles;

(C) Cumulative fractional release of ODS over 9 days upon activation once a day for $10 \mathrm{~min}\left(980 \mathrm{~nm}, 3 \mathrm{~W} \mathrm{~cm}^{-2}\right)$; (D) Concentration of photothermally released ODS into water $(\mathrm{pH} 7)$ from Kapton/rGO patch upon pulsed light irradiation at $980 \mathrm{~nm}$ and $3 \mathrm{~W} \mathrm{~cm}^{-2}$.

It has been previously demonstrated that photo-thermal ablation using pulsed rather than continuous laser light produces instant heating, which ceases at the end of each light pulse, resulting in much less temperature increase in the skin and favorable release [55]. In addition, the release profile of ODS under laser pulses of $100 \mathrm{~ms}$, with a dead time of $500 \mathrm{~ms}$, has been examined (Fig. 4D). Under laser light pulses activation, only a fraction of ODS was released when compared to that under continuous illumination (Fig. 4A). As the temperatures obtained using pulsed illumination were much lower than those under continuous one, it seems that the temperature plays a major role in the release.

\subsection{Transdermal ODS delivery through pig skin}

To determine the impact of NIR laser irradiation on the skin penetration ability and profile of ODS from Kapton/rGO-ODS patch reservoir, the transdermal flux of ODS through skin was investigated using a Franz diffusion cells set-up. Skin permeation studies were performed using

DOI: https://doi.org/10.1016/j.jconrel.2016.11.029 - Journal: Journal of Controlled Release - Postprint 
porcine ear skin since its stratum corneum is very similar to that of human stratum corneum [56]. The thickness of the skin was determined as being $1.6 \pm 0.4 \mathrm{~mm}$. As dry skin provides a significant barrier to drug diffusion, the pig skin was wetted before the deposition of the Kapton/rGO patch. The Kapton/rGO-ODS patch was irradiated for $10 \mathrm{~min}$ at $980 \mathrm{~nm}$ at different laser power densities between 0 and $10 \mathrm{~W} \mathrm{~cm}^{-2}$ and the passage of ODS through the skin was followed over $6 \mathrm{~h}$ and quantified using HPLC/UV (see SI Fig. S1) where a linear relationship between peak area and ODS concentration between 0.1 and $10 \mu \mathrm{gL}^{-1}$ is obtained, with a limit of detection of $0.1 \mu \mathrm{g} \mathrm{mL}{ }^{-1}$.

As can be seen from Fig. 5A, no passive transdermal diffusion of ODS was observed. This was validated both by depositing (1) ODS loaded Kapton/rGO patches onto the pig skin without laser stimulation or (2) when $200 \mu \mathrm{L}$ of an ODS solution $\left(100 \mu \mathrm{g} \mathrm{mL}^{-1}\right)$ were deposited on the skin. This is in line with reported data by others $[43,44]$.

(A)

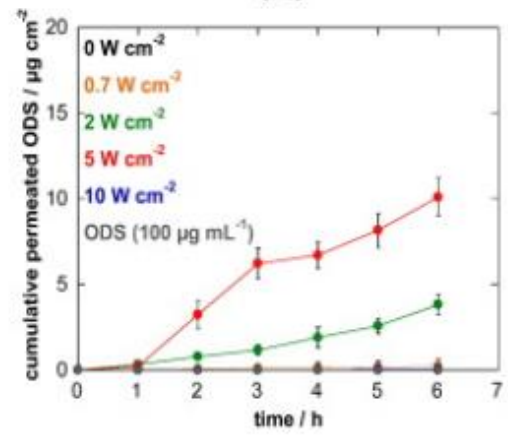

(C)

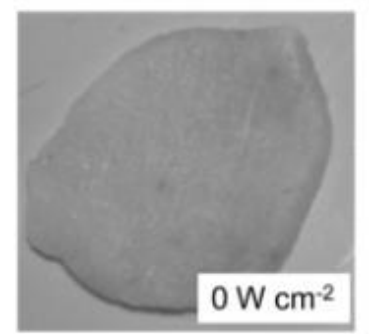

(B)
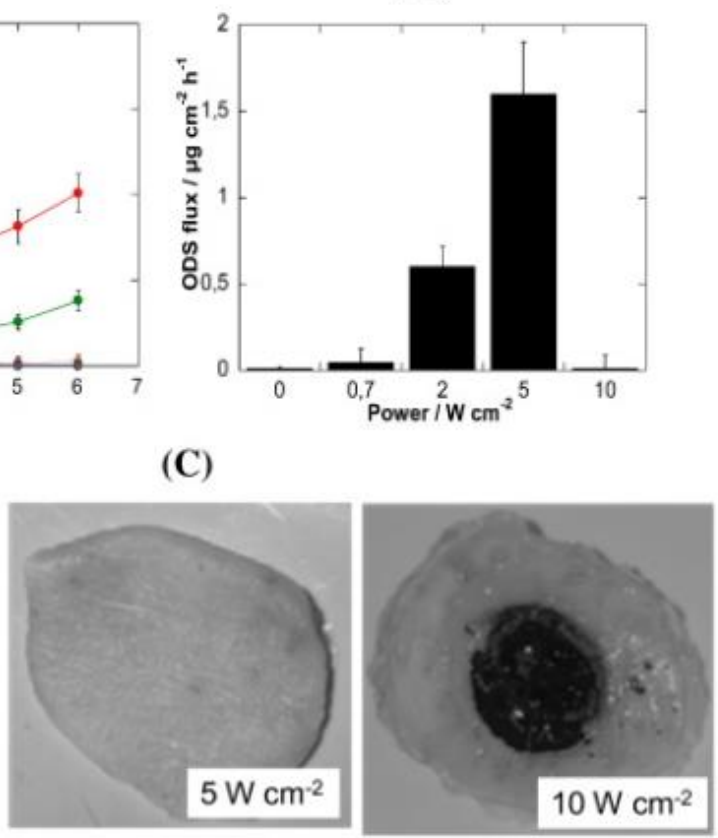

\section{Figure 5}

(A) In vitro permeation profiles of ODS (cumulative amount permeated vs time) through porcine skin from Kapton/rGO-ODS patches formed by mixing $500 \mu \mathrm{g} \mathrm{mL}^{-1}$ ODS with $1 \mathrm{mg} \mathrm{mL}^{-1} \mathrm{rGO}$ upon light irradiation for $10 \mathrm{~min}$ using a continuous wave laser at $980 \mathrm{~nm}$ at different laser power densities; $\left(0.7-10 \mathrm{~W} \mathrm{~cm}^{-2}\right)$;

(B) Flux of ODS determined from panel A;

(CD) Photographs of pig skin before and after laser irradiation at 5 and $10 \mathrm{~W} \mathrm{~cm}^{-2}$ for $10 \mathrm{~min}$.

In vitro release profiles of ODS upon laser irradiation indicate a laser power density correlated with increase in the quantity of ODS crossing the skin (Fig. 5A). After a lag time of about $1 \mathrm{~h}$, transdermal ODS delivery is observed when laser power densities of 2 and $5 \mathrm{~W} \mathrm{~cm}^{-2}$ were

DOI: https://doi.org/10.1016/j.jconrel.2016.11.029 - Journal: Journal of Controlled Release - Postprint 
used, with a more efficient penetration of ODS at the higher laser power density. While a constant increase of ODS permeation is seen in the case of $2 \mathrm{~W} \mathrm{~cm}^{-2}$, in the case of $5 \mathrm{~W} \mathrm{~cm}^{-2}$ ODS penetration is more effective in the first $3 \mathrm{~h}$, then stagnates with a reuptake at longer penetration times.

This enhancement is correlated to the temperature increase at the vicinity of the skin from $34{ }^{\circ} \mathrm{C}$ $\left(0.7 \mathrm{~W} \mathrm{~cm}^{-2}\right)$ to $41{ }^{\circ} \mathrm{C}\left(2 \mathrm{~W} \mathrm{~cm}^{-2}\right)$ and finally $60{ }^{\circ} \mathrm{C}\left(5 \mathrm{~W} \mathrm{~cm}^{-2}\right)$. Indeed, controlled heat application can significantly enhance local skin perfusion and drug uptake from patches with correlate with an increased ODS transdermal delivery [57]. Surprisingly, application of a laser power density of $10 \mathrm{~W} \mathrm{~cm}^{-2}$, which leads to even higher local temperature of $\approx 89^{\circ} \mathrm{C}$, shows no ODS passage over time. Such temperatures should result in a disorder of the lipid structures of the stratum corneum and probably in the disruption of the keratin network structures of stratum corneum, promoting drug penetration through the skin [36]. Different to laser ablation, in our case, the heat pulse is longer and heat propagation deeper into the tissue is expected, which might prevent ODS penetration, once damaged. Fig. 5C shows photographic images of the pig skin before and after laser irradiation at 5 and $10 \mathrm{~W} \mathrm{~cm}^{-2}$. It can be noticed, that while no significant burns are seen until laser power densities of $5 \mathrm{~W} \mathrm{~cm}^{-2}$, the pig skin was strongly burned at $10 \mathrm{~W} \mathrm{~cm}^{-2}$.

The results of the laser irradiation of ODS Kapton/rGO patches using power densities of $5 \mathrm{~W} \mathrm{~cm}{ }^{-2}$ were thus investigated in more details. To determine if the rest of the ODS, which has not passed the skin, is retained in the skin rather than passed through, the amount of skin trapped ODS left was determined. Indeed, from the $495 \mu \mathrm{g}$ ODS initially loaded on the Kapton/rGO patch, after $6 \mathrm{~h}, 70 \pm 10 \mu \mathrm{g}$ was found to be trapped in the skin. In total, $79.6 \mu \mathrm{g}$ ODS $(16 \%)$ has thus has been released from the skin patch upon illumination at $5 \mathrm{~W} \mathrm{~cm}^{-2}$, which is in accordance with results obtained in water (Fig. 4B).

From Fig. 5A, the ODS flux $(J)$ across pig skin at $5 \mathrm{~W} \mathrm{~cm}^{-2}$ irradiation was determined to be $J=3.1 \mu \mathrm{g} \mathrm{cm}^{-2} \mathrm{~h}^{-1}$ for the first $3 \mathrm{~h}$ and then to decrease to $J=1.6 \mu \mathrm{g} \mathrm{cm}^{-2} \mathrm{~h}^{-1}$ thereafter (Fig. 5B). These values are comparable to that reported by Mashru et al. at $\mathrm{pH} 7.4$ with an ODS flux of $J=2.52 \mu \mathrm{g} \mathrm{cm}^{-2} \mathrm{~h}^{-1}[58]$. The results are also in line with the permeation parameters of ODS through exercised hairless mouse skin with a flux of $J=4.04 \mu \mathrm{g} \mathrm{cm}^{-2} \mathrm{~h}^{-1}$ reported by Gwak et al. using binary diethylene glycol monoethyl ether (DGME)/propylene glycol manocaprylate (PGMC) vehicles with a DGME/PGMC ratio of 1/100 [45].

Considering that the usual oral dose of ODS is between 16 and $32 \mathrm{mg}$ a day and the oral bioavailability of ODS is $60 \%$, for an effective transdermal delivery system, about $10-20 \mathrm{mg}$ a day should be delivered via the skin into the blood circulation, i.e. 2.5-5 mg each $6 \mathrm{~h}$ [45]. Considering that a $25 \mathrm{~cm}^{2}$ patch could be used, an ODS delivery of about $480 \mu \mathrm{g}$ every $6 \mathrm{~h}$ can be reached, which would necessitate currently the use of several patches.

\subsection{Histological analysis of laser-irradiated pig skin}

The impact of the laser-irradiation on the skin structure was in addition taken into account by performing some histological investigations immediately after the laser activation experiments. Masson's trichrome dye was used for staining as it is commonly used in order to distinguish cells from a specific tissue from cells of other connective tissues by distinguishable colorations of each tissue. Using this dye, keratin and muscle fibers are colored red, collagen and bone blue 14

DOI: https://doi.org/10.1016/j.jconrel.2016.11.029 - Journal: Journal of Controlled Release - Postprint 
or green, cytoplasm red or pink, and cell nuclei are brown to black. As can be seen in Fig. 6, no significant histological changes were observed up to a laser power density of $2 \mathrm{~W} \mathrm{~cm}^{-2}$. In the case of $5 \mathrm{~W} \mathrm{~cm}^{-2}$, which resulted in a large enhanced ODS permeation, modification of the skin epidermis structure is noticed. A total disruption of the stratum corneum is observed, which is in line with the possibility of transdermal ODS delivery. The collagen cell structure changes to a keratin like (scar tissue).

\begin{tabular}{|c|c|c|c|c|}
\hline $\begin{array}{c}\text { Power density } \\
\left(\mathrm{W} \mathrm{cm}^{2}\right)\end{array}$ & 0 & 1 & 2 & 5 \\
\hline $\begin{array}{c}\text { Skin photography } \\
\text { after experimental } \\
\text { procedure }\end{array}$ & & & \\
\hline $\begin{array}{c}\text { Masson's } \\
\text { trichrome stain }\end{array}$ & & & \\
\hline
\end{tabular}

\section{Figure 6}

Representative photographes and histology of pig ear skin after treatment with different laser power densities at $980 \mathrm{~nm}$ for $10 \mathrm{~min}$. Scale bar $=0.5 \mathrm{~mm}$.; the black spots on the skin are due to rGO.

\subsection{Effect of addition of penetration enhancer on the ODS flux}

The addition of penetration enhancers to transdermal delivery systems is known to improve drug penetration through the skin either by altering the skin barrier or by modifying the thermodynamic activity of penetrates [32]. We opted for the use of surfactant Tween 20, a known efficient skin enhancer used for ODS transdermal delivery [44]. Fig. 7A shows the in vitro permeation profiles of ODS through porcine skin using either a skin patch where Tween 20 had been integrated into the rGO/ODs formulation and when the porcine skin was simply wetted with $200 \mu \mathrm{L}$ of a solution of Tween 20 (15 wt.\% in water) before the Kapton/rGO-ODS patch was placed onto the skin. Integration of Tween 20 into the skin patch (Kapton/rGO-ODStween 20) results in about 2.8 times higher permeated ODS, with an ODS flux of $4.49 \mu \mathrm{g} \mathrm{cm}^{-2} \mathrm{~h}^{-1}$. However, the ODS flux was significantly enhanced to $13.2 \pm 1.5 \mu \mathrm{g} \mathrm{cm}^{-2} \mathrm{~h}^{-1}$ when Tween 20 was directly deposited onto the pig skin and not integrated into the patch formulation. With a skin patch of $25 \mathrm{~cm}^{2}$ about $2 \pm 0.2 \mathrm{mg}$ of ODS are delivered every $6 \mathrm{~h}$, a therapeutically correct dose.

DOI: https://doi.org/10.1016/j.jconrel.2016.11.029 - Journal: Journal of Controlled Release - Postprint 
(A)

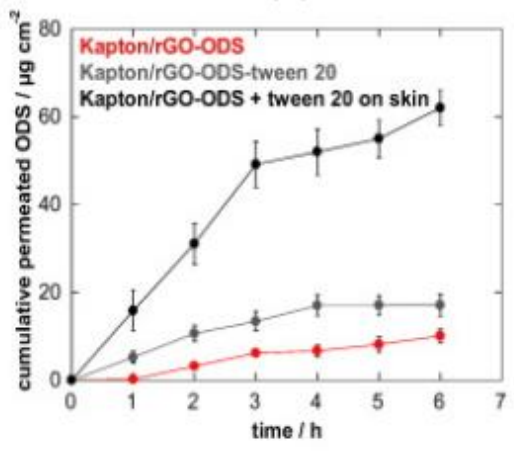

(B)

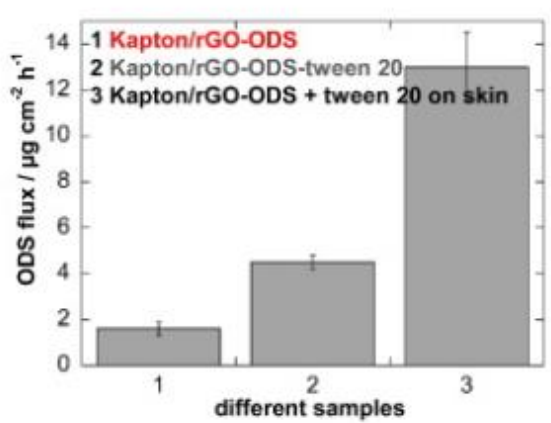

\section{Figure 7}

In vitro permeation profiles of cumulative permeated ODS through porcine skin upon light irradiation for 10 min using a continous wave laser at $980 \mathrm{~nm}$ at $5 \mathrm{~W} \mathrm{~cm}^{-2}$ ) from Kapton/rGO-ODS (red; formed by mixing $500 \mu \mathrm{g} \mathrm{mL} \mathrm{m}^{-1}$ ODS with $1 \mathrm{mg} \mathrm{mL}^{-1}$ rGO), Kapton/rGO-ODS-tween 20 impregnated patches (grey; formed by mixing $500 \mu \mathrm{g} \mathrm{mL}^{-1}$ ODS with $500 \mu \mathrm{g} \mathrm{mL}^{-1}$ tween 20 and $1 \mathrm{mg} \mathrm{mL}^{-1} \mathrm{rGO}$ ) and from Kapton/rGO-ODS by wetting the skin with tween $20(200 \mu \mathrm{L}, 15$ wt.\% in water); (B) Flux of ODS determined.

\section{Conclusion}

In summary, we have developed a new strategy for the transdermal delivery of drugs using a composite patch based on Kapton modified with reduced graphene oxide (rGO). Ondansetron (ODS), a common drug to limit chemotherapy induced nausea and vomiting was used as a model drug to validate the concept. While ODS has a very good oral bioavailability, good water solubility and low molecular weight, its low permeability does not allow passive transdermal delivery. We could show that the use of ODS loaded Kapton/rGO patch upon laser-irradiation at $980 \mathrm{~nm}$ for $10 \mathrm{~min}$ results in an enhanced skin penetration without the use of permeation enhancers. The release strategy is based on a photothermally induced temperature increase, which modulates the affinity of ODS to rGO, and results in a controlled ODS release from the patch. Using porcine ear skin as a model the cumulative quantity of ODS passing the skin and the ODS flux are highly dependent on the laser power density used. At $5 \mathrm{~W} \mathrm{~cm}^{-2}$ irradiation, the ODS flux across pig skin was determined to be $1.6 \mu \mathrm{g} \mathrm{cm}^{-2} \mathrm{~h}^{-1}$. The transdermal ODS dose delivered is smaller than the expected dose necessary for a therapeutic effect. However, the ODS flux could be increased to $13.2 \mu \mathrm{g} \mathrm{cm}^{-2} \mathrm{~h}^{-1}$ when Tween 20 was used for skin wetting. With a skin patch of $25 \mathrm{~cm}^{2}$, a delivery of about $2 \mathrm{mg}$ every $6 \mathrm{~h} \mathrm{[45]} \mathrm{can} \mathrm{thus} \mathrm{be} \mathrm{reached.}$

These results showing the potential of photothermal transdermal delivery using appropriate skin patches are encouraging and might open up new avenues for the development of NIR assisted transdermal delivery of different drugs using photothermal nanostructures. An intrinsic advantage for the proposed approach is that rGO is not delivered at the same time as the drug under consideration, minimizing regulatory issues as well as safety and toxicity issues. The fabrication costs of these skin patches are low as rGO can be produced on large scale industrially and as only small quantities of rGO $(1 \mathrm{mg} / \mathrm{mL})$ is needed for the fabrication of a patch. Furthermore, these patches can be easily recharged with ODS or any drug of interest by

DOI: https://doi.org/10.1016/j.jconrel.2016.11.029 - Journal: Journal of Controlled Release - Postprint 
simple immersing Kapton/rGO into the respective solution. We believe that all these criteria make this photoactivable patch at demand an interesting alternative to other ODS formulations.

\section{Acknowledgements}

R.B. and S.S. gratefully acknowledge financial support from the Centre National de la Recherche Scientifique (CNRS), the Lille1 University, the CPER "Photonics for Society", and the Hauts-de-France Region. S.S thanks the Institut Universitaire de France (IUF) for financial support. Support from the European Union through H2020-MSCA-RISE-2015 (No. 690836, PANG) is also acknowledged.

\section{References}

1. M. Bikram, J.L. West Thermo-responsive systems for controlled drug delivery Expert Opin. Drug Deliv., 10 (2008), pp. 1077-1091

2. L. Deng, J. Ren, J. Li, J. Leng, Y. Qu, C. Lin, D. Shi Magnetothermally responsive star-block copolymeric micelles for controlled drug delivery and enhanced thermo-chemotherapy Nanoscale, 7 (2015), pp. 9655-9663

3. S. Goenka, V. Sant, S. Sant Graphene-based nanomaterial for drug delivery and tissue engineering

J. Control. Release, 173 (2014), pp. 75-88

4. J.S. Im, B.C. Bai, Y.-S. Lee The effect of carbon nanotubes on drug delivery in an electro-sensitive transdermal drug delivery system

Biomaterials, 31 (2010), pp. 1414-1419

5. D.A. La Van, T. McGuire, R. langer Small-scale systems for in vivo drug delivery Nat. Biotechnol., 21 (2003), p. 1184

6. S. Mura, J. Nicolas, P. Couvreur Stimuli-responsive nanocarriers for drug delivery Nat. Mater., 12 (2013), pp. 991-1003

7. D. Peer, J.M. Karp, S. Hong, O.C. Farokhzad, R. Margalit, R. Langer Nanocarriers as an emerging platform for cancer therapy

Nat. Nanotechnol., 2 (2007), p. 751

8. C.L. Stevenson, J.T. Santini, R. Langer Reservoir-based drug delivery systems using microtechnology

Adv. Drug Deliv. Rev., 64 (2012)

9. W. He, X. Guo, M. Zhang Transdermal permeation enhancement of $N$-trimethyl chitosan for testosterone

Int. J. Pharm., 356 (2008), pp. 82-87

10. H. Lee, T.K. Choi, Y.B. Lee, H.R. Cho, R. Ghaffari, L. Wang, H.J. Choi, T.D. Chung, N. Lu, T. Hyeon, S.H. Choi, D.-H. Kim A graphene-base electrochemical device with thermoresponsive microneedles for diabetes monitoring and therapy Nat. Nanotechnol. (2016)

11. F. Teodorescu, L. Rolland, V. Ramarao, A. Abderrahmani, D. Mandler, R. Boukherroub, S. Szunerits Electrochemically triggered release of human insulin from an insulin-impregnated reduced graphene oxide modified electrode Chem. Commun., 51 (2015), pp. 14167-14170

DOI: https://doi.org/10.1016/j.jconrel.2016.11.029 - Journal: Journal of Controlled Release - Postprint 
12. J. Hong, N.J. Shah, A.C. Drake, P.C. DeMurth, J.B. Lee, J. Chen, P.T. Hammond Graphene multilayers as gates for multi-week sequential release of proteins from surfaces ACS Nano, 6 (2012), pp. 81-88

13. X. Yang, X. Zhang, Z. Liu, Y. Ma, Y. Huang, Y. Chen High-efficiency loading and controlled release of doxorubicin hydrochloride on graphene oxide J. Phys. Chem. C, 112 (2008), pp. 17554-17558

14. K. Turcheniuk, A. Mororina, P. Subramanian, A. Barras, V. Zaitsev, V. Kuncser, A. Leca, A. Martoriati, K. Cailliau, J.-F. Bodart, R. Boukherroub, S. Szunerits Insulin loaded iron magnetic nanoparticles-graphene oxide composites: synthesis, characterization and application for diabetes treatment RSC Adv., 4 (2014), pp. 865-875

15. H. Kim, W.J. Kim Photothermally controlled gene delivery by reduced graphene oxide-polyethylenimine nanocomposite Small, 10 (2014), pp. 117-126

16. Z. Liu, J.T. Robinson, X. Sun, H. Dai PEGylated nanographene oxide for delivery of water-insoluble cancer drugs

J. Am. Chem. Soc., 130 (2008), pp. 10876-10877

17. L. Zhang, J. Xia, Q. Zhao, L. Liu, Z. Zhang Functional graphene oxide as a nanocarrier for controlled loading and targeted delivery of mixed anticancer drugs Small, 6 (2010), pp. 537-544

18. C.L. Weaver, J.M. LaRosa, X. Luo, X.T. Cui Electrically controlled drug delivery form graphene oxide nanocomposite films

ACS Nano, 8 (2014), pp. 1834-1843

19. N.M. Kenna, P. Calvert, A. Morrin, G.G. Wallace, S.E. Moulton Electro-stimulated release from a reduced graphene oxide composite hydrogel

J. Mater. Chem. B, 3 (2015), p. 2530

20. P. Matteini, F. Tatini, L. Cavigili, S. Ottaviano, G. Ghini, R. Pini Graphene as a photothermal switch for controlled drug release Nanoscale, 6 (2014), p. 7947

21. Z. Yan, D. zhao, X. Yi, R. Zhuo, F. Li Steric protected and illumination-activated tumor targeting accessory for endowing drug-delivery system with tumor selectivity

Adv. Funct. Mater., 24 (2014), pp. 1799-1807

22. D. Wang, S. Wu Red-light responsive supramolecular valves for photocontrolled drug release from mesoporous nanoparticle

Langmuir, 32 (2016), pp. 632-636

23. Y.-W. Wang, Y.-Y. Fu, Q. Peng, S.-S. Guo, G. Liu, J. Li, H.-H. Yang, G.-N. Chen Dyeenhanced graphene oxide for photothermal therapy and photoacoustic imaging J. Mater. Chem. B, 1 (2013), pp. 5762-5767

24. Z.M. Markovic, L.M. Harhaji-Trajkovic, B.M. Todorovic-Markovic, D.P. Kepoc, K.M. Arsikin, S.P. Jovanovic, A.C. Pantovic, M.D. Dramicanina, V.S. Trajkovic In vitro comparison of the photothermal anticancer activity of graphene nanoparticles and carbon nanotubes

Biomaterials, 32 (2011), p. 1121

25. B.P. Timko, M. Arruebo, S.A. Shankrappa, J.B. McAlvin, O.S. Okonkwo, B. Mizrahi, C.F. Stefanescu, L. Gomez, J. Zhu, A. Zhu, J. Santamaria, R. Langer, D.S. Kohane Near-infrared(actuated devices for remotely controlled drug delivery)

DOI: https://doi.org/10.1016/j.jconrel.2016.11.029 - Journal: Journal of Controlled Release - Postprint 
PNAS, 111 (2014), pp. 1349-1354

26. E. Akhavan, E. Ghaderi Graphene nanomesh promises extremely efficient in vivo photothermal therapy

Small, 9 (2013), p. 3593

27. T. Taqnner, R. Marks Delivering drugs by the transdermal route: review and comments

Skin Res. Technol., 14 (2008), pp. 249-260

28. G. Cevc, G. Blume, A. Schatzlein, D. Gebauer The skin: a pathway for systematic treatment with patches and lipid-based carriers

Adv. Drug Deliv. Rev., 18 (1996), pp. 349-378

29. D.P. Wermeling, S.L. Banks, D.A. Hudson, H.S. Gill, J. Gupta, M.R. Prausnitz, A.L. Stinchcomb Microneedles permit transdermal delivery of a skin-impermeant medication to humans PNAS, 105 (2008), pp. 2058-2063

30. M.R. Prausnitz, S. Mittagotri, R. Langer Current status and future potential of transdermal drug delivery

Nat. Rev. Drug Discov., 3 (2004), pp. 115-124

31. T. Hampton Breaking barriers in transdermal drug delivery

J. Am. Med. Assoc., 293 (2005), p. 2083

32. A.C. Williams, B.W. Barry Penetration enhancers

Adv. Drug Deliv. Rev., 56 (2004), pp. 603-618

33. H.K. Vaddi, et al. Human skin penetration of branched chain 3-O-alkyl ester and carbonate prodrugs of naltrexone Pharm. Res., 22 (2005), pp. 758-765

34. Y. Chen, Y. Shen, X. Gui, C. Zhang, W. Yang, M. Ma, S. Liu, M. Zhang, L.P. Wen Transdermal protein delivery by coadminstered peptides identified via phage display Nat. Biotechnol., 24 (2006), pp. 455-460

35. S. Yang, F. Wu, J. Liu, G. Fan, W. Welsh, H. Zhu, T. Jin Phase-transition microneedle patches for efficient and accurate transdermal delivery of insulin Adv. Mater., 25 (2015), pp. 4633-4641

36. Y. Li, L. Guo, W. Lu Laser ablation-enhanced transdermal drug delivery Photon Lasers Med., 2 (2013), pp. 315-322

37. M.R. Prausnitz, R. Langer Transdermal drug delivery Nat. Biotechnol., 26 (2008), pp. 1261-1268

38. J. Vanakoski, T. Seppala Heat exposure and drugs. A review of the effects of hyperthermia and pharmacokinetics Clin. Pharmacokinet., 34 (1998), pp. 311-322

39. K.K. Peersen, M.L. Rousing, C. Jensen, L. Arendt-Nielsen, P. Gazerani Effect of local controlled heat on transdermal delivery of nicotin Int. J. Physiol. Pathophysiol. Pharmacol., 3 (2011), pp. 236-242

40. B.P. Timko, D.S. Kohane Prospects for near-infrared technology in remotely triggered drug delivery

Expert Opin., 11 (2014), pp. 1681-1685

41. R. Patel, S. Naik, J. Patel, A. Baria Formulation development and evaluation of mouth melting film of ondansetron

Arch. Pharm. Sci. Res., 1 (2009), p. 212

DOI: https://doi.org/10.1016/j.jconrel.2016.11.029 - Journal: Journal of Controlled Release - Postprint 
42. B. Godin, E. Touitou Transdermal skin delivery: predictions for human from in vivo, ex vivo and animal models

Adv. Drug Deliv. Rev., 59 (2007), pp. 1152-1161

43. A.S. Can, M.S. Erdal, S. Gungor, Y. Ozsoy Optimization and characterisation of chitosan films for transdermal delivery of ondansetron

Molecules, 18 (2013), pp. 5455-5471

44. R.M. Al Abood, S. Talegaonkar, M. Tariq, F.J. Ahmad Microemulsion as a tool for the transdermal delivery of ondansetron for the treatment of chemotherapy induced nausea and vomiting

Colloids Surf. B, 101 (2013), pp. 143-151

45. H.S. Gwak, I.S. Oh, I.K. Chun Transdermal delivery of ondansetron hydrochloride: effects of vehicles and penetration enhancers

Drug Dev. Ind. Pharm., 30 (2004), pp. 187-194

46. O. Fellahi, M.R. Das, Y. Coffinier, S. Szunerits, T. Hadjersi, M. Maamache, R. Boukherroub Silicon nanowire arrays-induced graphene oxide reduction under UV irradiation

Nanoscale, 3 (2011), pp. $4662-4669$

47. S. Stankovich, D.A. Dikin, R.D. Piner, K.A. Kohlhaas, A. Kleinhammes, Y. Jia, Y. Wu, S.T. Nguyen, R.S. Ruoff Synthesis of graphene-based nanosheets via chemical reduction of exfoliated graphite oxide Carbon, 45 (2007), p. 1558

48. P. A Sensor Applications of Polyimides InTech (2012), pp. 199-214 (Chapter 10)

49. D. Wilson, H.D. Stenzenberger, P.M. Hergenrother Polyimides Chapman \& Hall, London (1990)

50. D. Sui, Y. Huang, L. Hung, J. Liang, Y. Ma, Y. Chen Flexible and transparent electrothermal film heaters based on graphene materials Small, 7 (2011), pp. 3186-3192

51. Y.M. Bae, Y.I. Park, S.H. Nam, J.H. Kim, K. Lee, H.M. Kim, B. Yoo, J.S. Choi, K.T. Lee, T. Hyeon, Y.D. Suh Endocytosis, intracellular transport, and exocytosis of lanthanide-doped upconverting nanoparticles in single living cells

Biomaterials, 33 (2012), pp. 9080-9086

52. S.H. Nam, Y.M. Bae, B.J. Park, J.H. kim, H.M. Kim, J.S. Choi, K.T. Lee, T. Hyeon, Y.D. Suh Long-term real-time tracking of lanthanide ion doped upconverting nanoparticles in living cells

Angew. Chem. Int. Ed., 50 (2011), pp. 6093-6097

53. W.R. Lee, S.C. Shen, K.H. Wang, C.H. Hu, J.Y. Fang The effect of laser treatment on skin to enhance an control transdermal delivery of 5-fluorouracil

J. Pharm. Sci., 91 (2002), pp. 1613-1626

54. R. Kaufmann, C. Beier Laser skin ablation: an update on aesthetic and medical indications

Med. Laser Appl, 19 (2004), pp. 212-222

55. S. Ramadan, L. Guo, Y. Li, B. Yan, W. Lu Hollow copper sulfide nanoparticlemediated transdermal drug delivery

Small, 8 (2012), pp. 3143-3150

56. K. Guth, M. Schäfer-Korting, E. Fabian, R. Landsiedel, B. van Ravenzwaay Suitability of skin integrity tests for dermal absorption studies in vitro

Toxicology, 29 (2015), pp. 113-123

DOI: https://doi.org/10.1016/j.jconrel.2016.11.029 - Journal: Journal of Controlled Release - Postprint 
57. K.K. Petersen, M.L. Rousing, C. Jensen, L. Arendt-Niemsen, P. Gazerani Effect of local controlled heat on transdermal delivery of nicotin

Int. J. Physciol. Pathophysiol. Pharmacol., 3 (2011), pp. 236-242

58. R.C. Mashru, V.B. Sutariya, M.G. Sankalia, J.M. Sankalia

Effect on $\mathrm{pH}$ on in vitro permeation of ondansetron hydrochloride across porcine buccal mucosa

Pharm. Dev. Technol., 10 (2005), pp. 241-247

DOI: https://doi.org/10.1016/j.jconrel.2016.11.029 - Journal: Journal of Controlled Release - Postprint 